ARTIFICIAL SATELLITES, Vol. 42, No. 4 - 2007

DOI: $10.2478 / v 10018-008-0010-3$

\title{
A BRIDGE DEFLECTION MONITORING WITH GPS
}

\author{
M. Figurski, M. Gałuszkiewicz, M. Wrona \\ The Applied Geomatics Section \\ Faculty of Civil Engineering and Geodesy \\ Military University of Technology \\ ul. Kaliskiego 2, 00-908 Warsaw, Poland \\ e-mail: mfigurski@wat.edu.pl,mgaluszkiewicz@wat.edu.pl,mwdriver@wp.pl
}

\begin{abstract}
This paper introduces results of investigation carried on by The Applied Geomatics Section in Military University of Technology. Research includes possibilities of monitoring dynamic behavior of a bridge using high rate GPS data. Whole event was executed with collaboration of The Road and Bridge Management and The Warsaw Geodesy Company. Interdisciplinary approach with this project allows authors to get reliable information about investigating constructions and their respond for true traffic loading detected by GPS receivers. Way of compute data and used software (TRACK) are also shown in this paper.
\end{abstract}

Keywords: GNSS, GPS, structural monitoring, bridge deflations

\section{INTRODUCTION}

For about twelve years scientists from couple of world famous universities have been working on using GPS data to detect deformations of big structures like tall buildings, long bridges or dams (Beser and Parkinson, 1982). As they say, they success. Main elements of monitoring system includes high sample rate GNSS receivers and software able to calculate phase measurements to sub centimeter values (Roberts et al., 2003; Roberts et al., 2004; Cosser, 2004)

The Applied Geomatics Sectionin Military University of Technology began studies to develop reliable method of structure health monitoring using GPS phase observations (Figurski et al., 2007). Whole project includes laboratory and bridges trials. Result of two bridges measurement projects are introduce in this paper: “im. Obrońców Modlina 1939" in Zakroczym and Siekierkowski Bridge in Warsaw. 


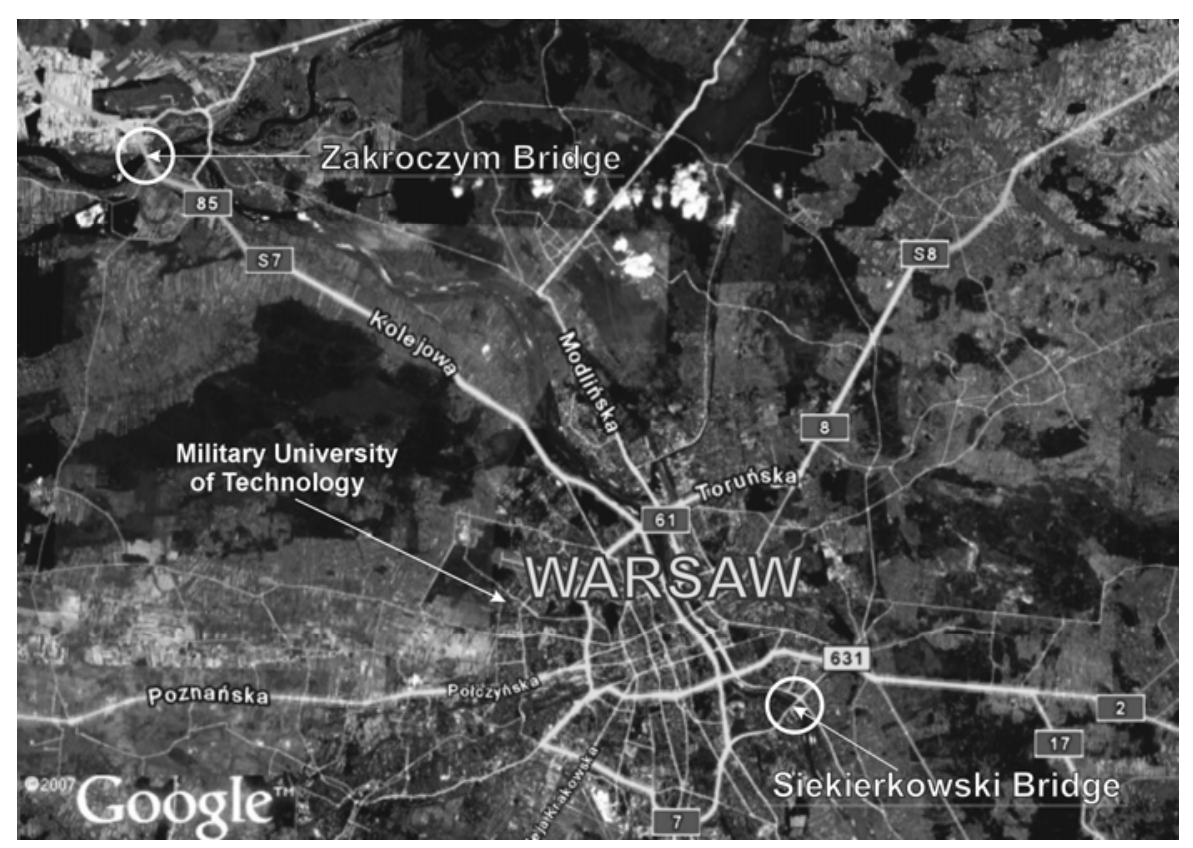

Fig. 1. Bridges location

\section{ZAKROCZYM BRIDGE TRIAL}

The bridge is situated on a road S7 (Fig.1). Investigated construction has 6 spans: two 75,0 m long and four 95,0 m long (Fig.2 A). Trial started at 3 p.m. and contained 5 hours of measurements. During this time loading of the construction is mainly caused by single trucks (42 t) crossing the bridge. Five geodetic GPS receivers were used: two $20 \mathrm{~Hz}$ receivers across second span, two $10 \mathrm{~Hz}$ receivers across third span and one $20 \mathrm{~Hz}$ as a reference station. Video camera situated between second and third span captured type o vehicles crossing the bridge. Five hours movie and GPS data synchronization enables to figure out what kind of vehicle cause such deformations. 


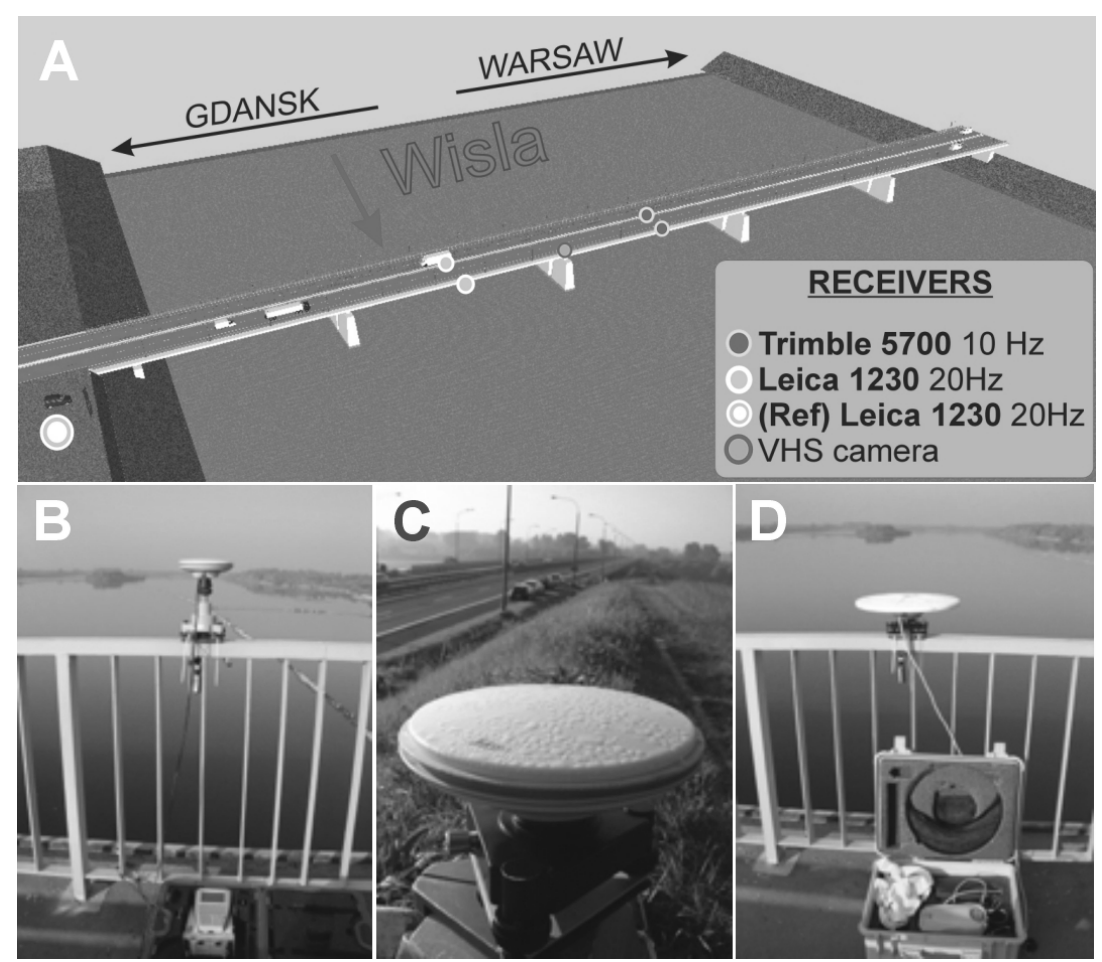

Fig. 2. A- Receivers localization; B- Leica 1230 (20Hz); C- Reference Station Leica 1230 $(20 \mathrm{~Hz})$; D- Trimble $5700(10 \mathrm{~Hz})$

Results

To calculate results, all collected GPS data were converted to the RINEX format and split to 1 hour files. To get best result, precise ephemeris were used (Lamparski, 2001; Spetch, 2007). Test with using rapid and ultra-rapid ephemeris didn't afford satisfying results because distance between receivers and reference station was about $150 \mathrm{~m}$.

Analysis process contained two steps. In first, GPS data and stability of kinematic solution were investigated. In second step, results were referred to the bridge construction (Chmielewski and Zębaty, 1998; Czudek and Wysocki, 2005). This interdisciplinary attitude engaged physics, bridge and geodesy specialists in this project.

Two characteristic cases are described below. In first, single cargo car load is analyzed, second shows set of heavy cars passing through the bridge.

Figure $3 \mathrm{~A}$ and $3 \mathrm{~B}$ shows absolute high displacement caused by single cargo cars pass the bridge. Truck entering shown on figure 3 can be clearly detected. Deflections increases to 2-3 $\mathrm{cm}$. It was the most often value for cargo car (42 tons) type. 


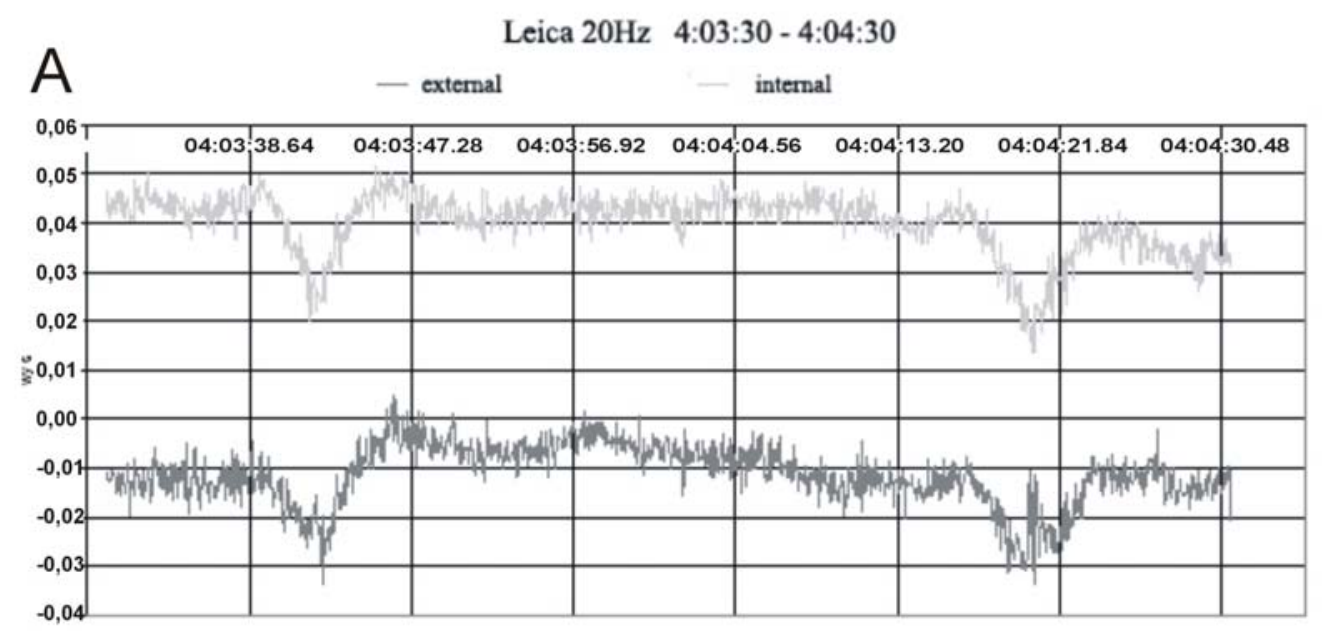

B

Trimble $10 \mathrm{~Hz}$ 4:03:30 - 4:04:30

displacement [m]

- external

- internal
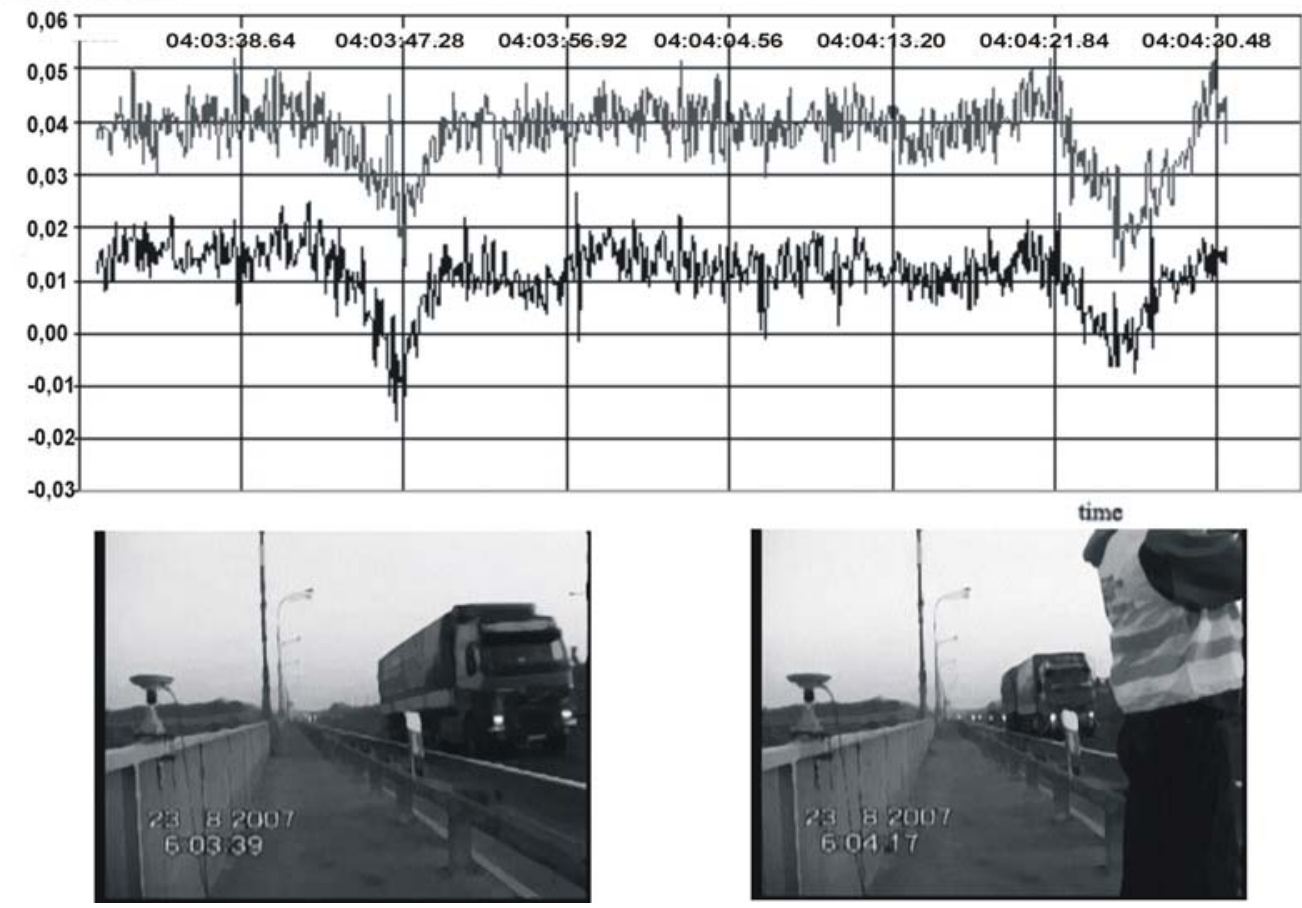

Fig. 3. Construction deflection caused by single trucks. A- (Leica $20 \mathrm{~Hz})$; B-(Trimble $10 \mathrm{~Hz})$

Figure 4 A describes real deflection curve progress (lighter one) caused by $30 \mathrm{t}$ loading car moving with speed of $97,7 \mathrm{~km} / \mathrm{h}$. Truck speed was recognized by distance between Leica and Trimble receivers $(95 \mathrm{~m})$. 


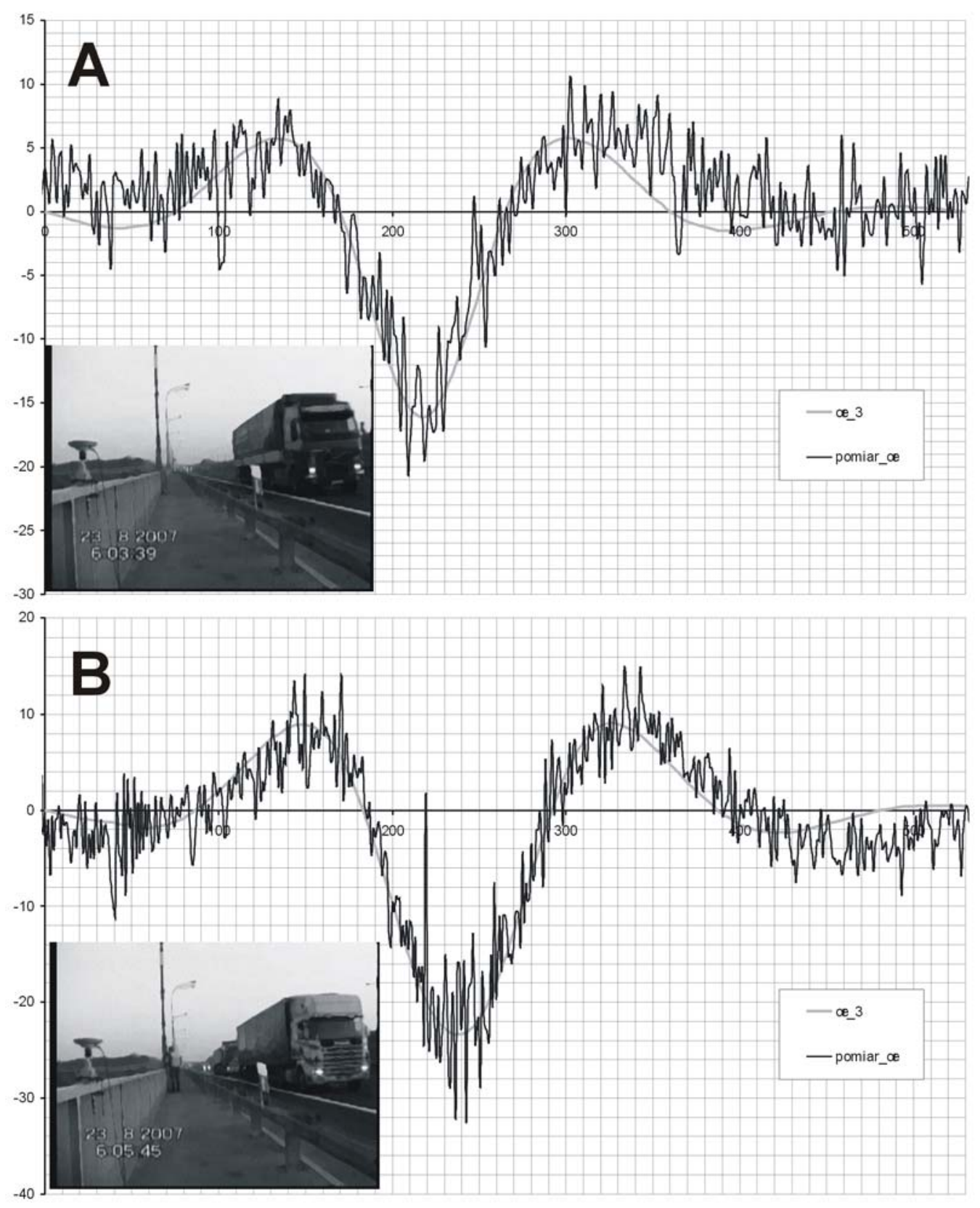

Fig. 4. Comparison of GPS and theoretic values of vertical displacement caused by: A single truck; B - two trucks one after other

Figure 4 B shows detected displacement caused by two trucks, rated 30 tons each. Cars were moving trough the bridge with speed of $72,8 \mathrm{~km} / \mathrm{h}$, distance between trucks was about $40 \mathrm{~m}$.

Figure 5 illustrates displacement recorded by Trimble 5700 situated on both sides of the road. It can be easily notice that left side of the road goes up when trucks cross the bridge. Right side goes down in the same time. Theoretic values were computed with using information about bridge construction and Finite Element Method. Result shows possibility of detection not only vertical movements of construction, but also torsions of each element. 


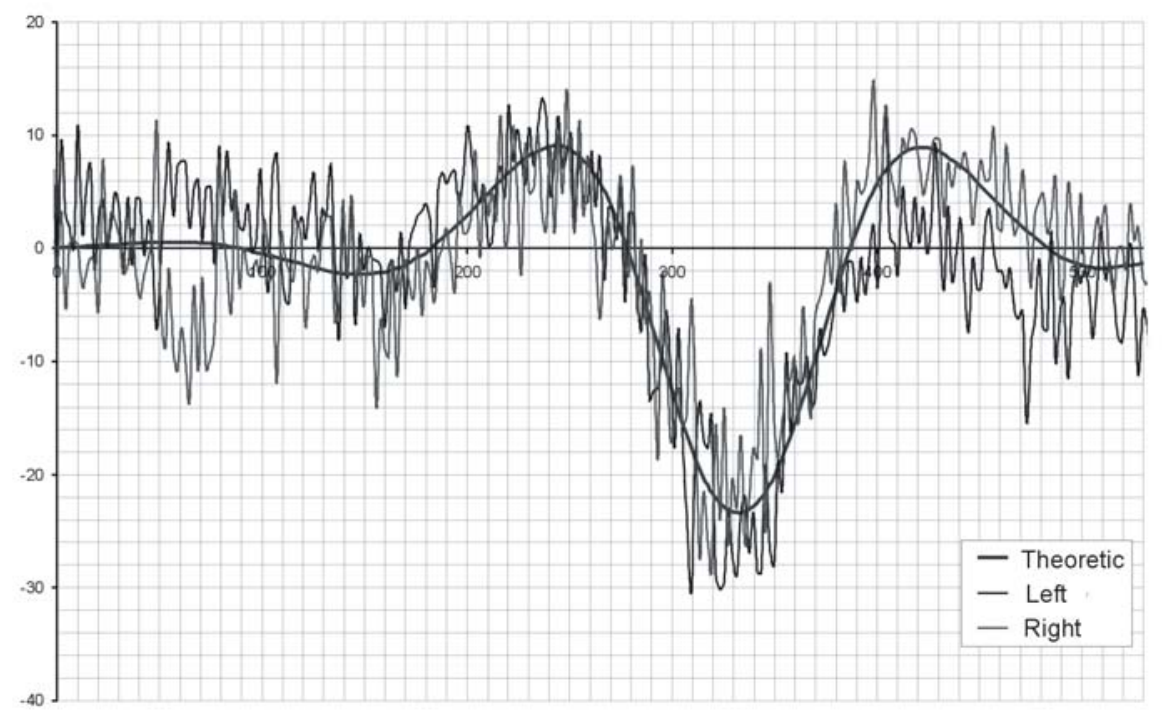

Fig. 5. Detection of torsions of the road caused by truck crossing by at one side of the road

\section{SIEKIERKOWSKI BRIDGE TRIAL}

Next bridge trial have been carried on during 25 September night in 2008. As in Zakroczym, five hours data was collected from 3 to 8 a.m.. This campaign included apart of Military Academy of Technology crew (The Applied Geomatics Section), The Warsaw Geodesy Company with special participation of The Road and Bridge Management and. Thanks to cooperation of these entities, nine GPS receivers could be used: two Trimble $5700(10 \mathrm{~Hz})$ and seven Leica $1230(20 \mathrm{~Hz})$. Two from seven Leica receivers were used as reference. Movement detectors (GPS receivers) were located across middle part of the main span and also on the top of every pylon (Fig. 6). Authors assumed that pylons movement can be detected during intensive load of the main span.

Time of the event was assigned for midnight hours when the main load of the construction is caused by single cargo trucks. To precise identify extortions, three video cameras were located in trial field (Przywara, 2007).

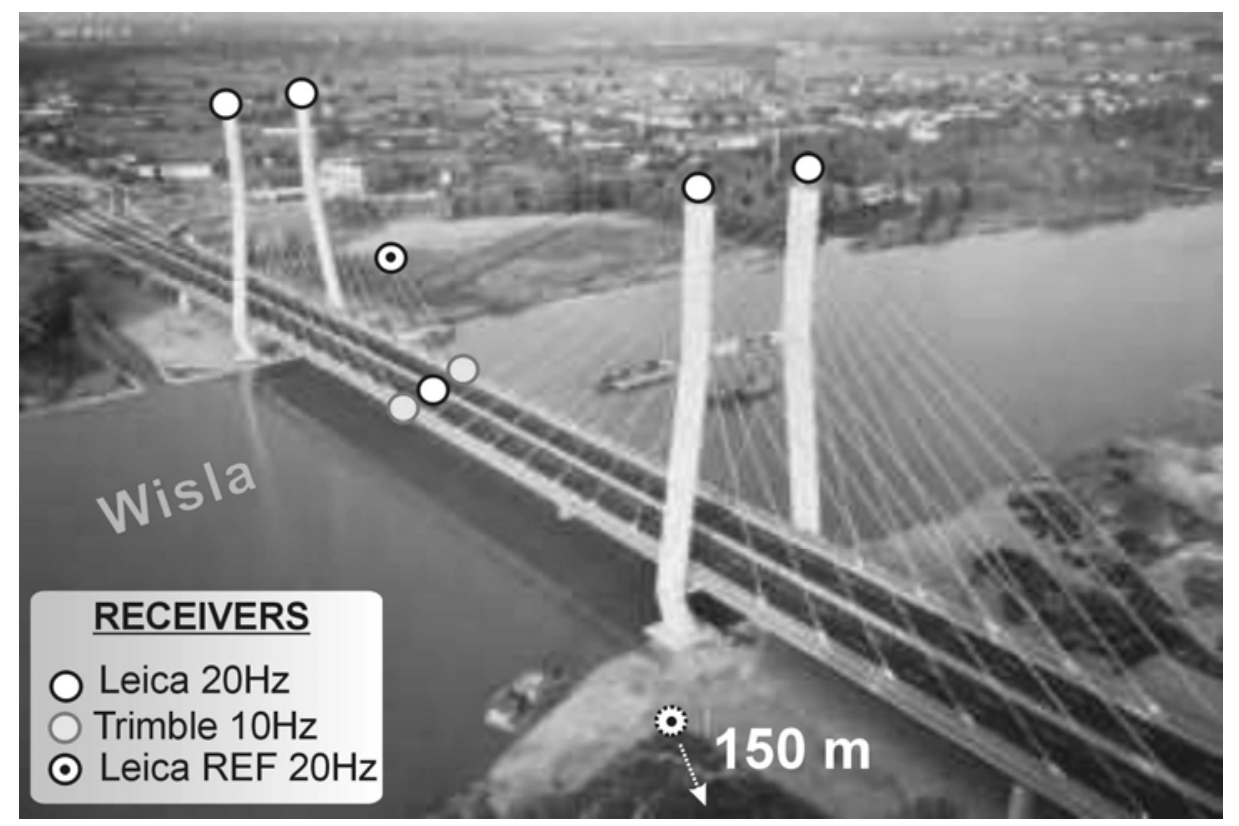

Fig. 6. Receivers localization 
Siekierkowski Bridge is the second longest suspension bridge in Poland (suspended bridge with the longest span was open two years ago in Płock - main span is 375 meters long). Main span of the Siekierkowski bridge is 250 meters long. Suspended part of the construction has total length 500 meters. Dimensions of the main parts of the bridge are shown on Fig. 7.

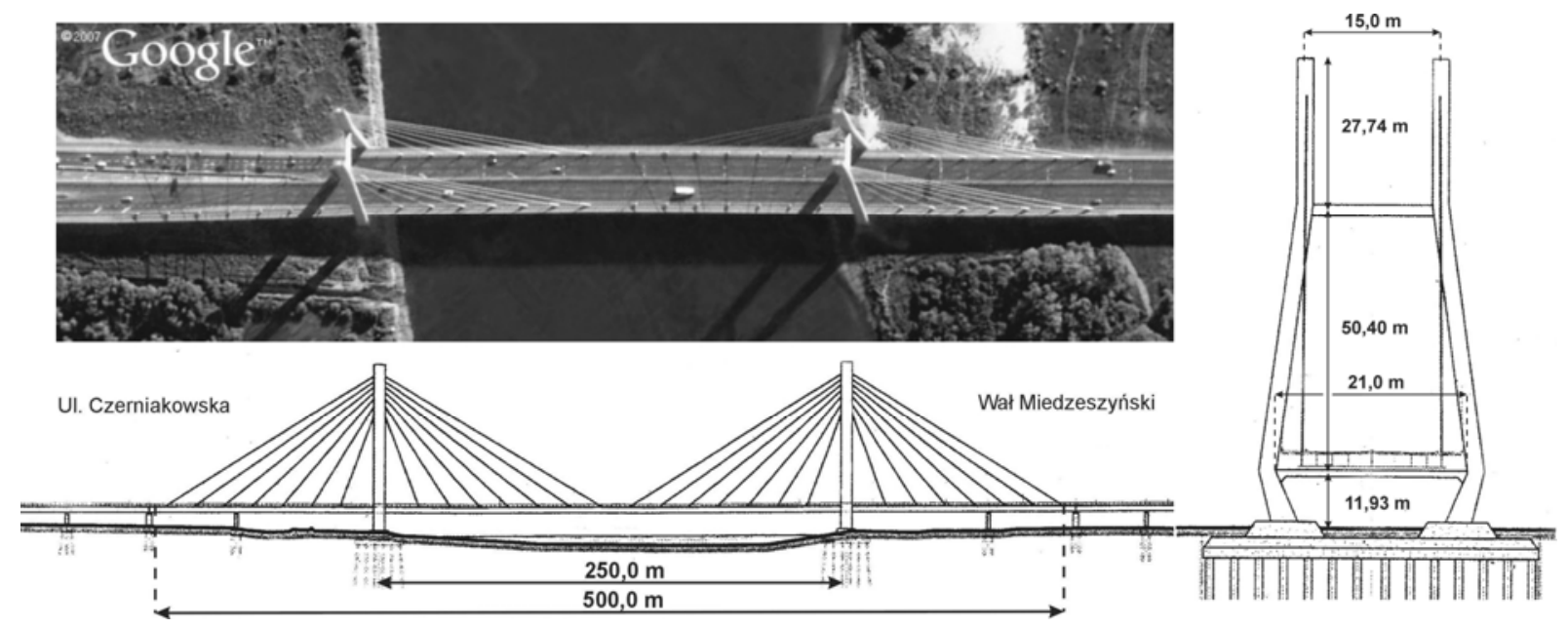

Fig. 7. Siekierkowski bridge dimensions

Results

Sample results of campaign are described below. First plot from the top describes detection of vertical movement of the main span caused by two cargo cars crossing the bridge one after another (Fig. 8 A). Two plots below shows change of distance between opposite pylons. Effect of construction work can be easily seen. When main span is forced by dynamic loading, distance between opposite pylons is visibly decreasing. Figure $8 \mathrm{~B}$ shows similar situation. 

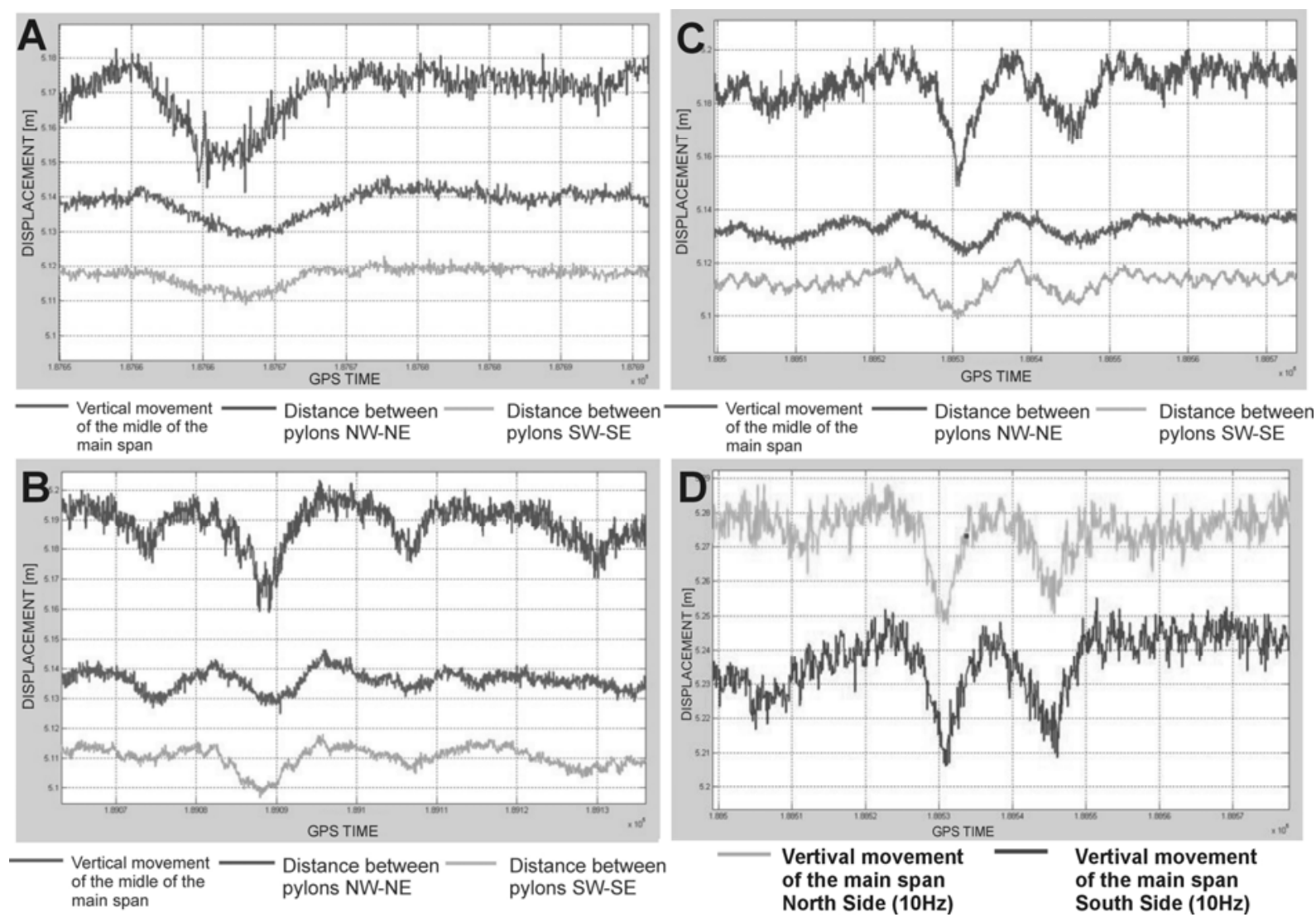

Fig. 8. Construction elements displacement detected by $20 \mathrm{~Hz}$ (A, B, C) and $10 \mathrm{~Hz}$ (D) receivers

Figure $8 \mathrm{C}$ shows the same displacement caused by set of cargo cars. First, set of two trucks were moving through the bridge. Six seconds later, another set of two truck were passing through. Vehicles were going from the different sides, so loading of the main span was quite uniform what is confirmed by data from $10 \mathrm{~Hz}$ receivers located in external sides of the road (Fig. 8 D).

\section{SOFTWARE}

To compute data TRACK application was used (King at el., 2006). Trajectory Calculation with Kalman Filter (developed by Massachusetts Institute of Technology) have been used primarily to work with $1 \mathrm{~Hz}$ data. Authors have changed algorithms to read $10 \mathrm{~Hz}$ and $20 \mathrm{~Hz}$ data so high sample rate information could be compute. Kalman filtering is used in TRACK software to get antenna position with centimeter accuracy using GPS, ephemeredes and atmospheric information.

This filtering technique was brought by Rudolf Kalman. It is a recursive filter that estimates the state of dynamic system of noisy measurements. The state of the system is often represented as a vector.

Kalman filters are based on linear dynamical systems discretised in the time domain. They are modeled on a Markov chain built on linear operators perturbed by Gaussian noise. At each discrete time increment, a linear operator is applied to the state to generate the new state, with noise mixed in, and optionally information from the controls on the system if they are known. Then, another linear operator mixed with more noise generates the visible outputs from the hidden state (Fig. 9). 


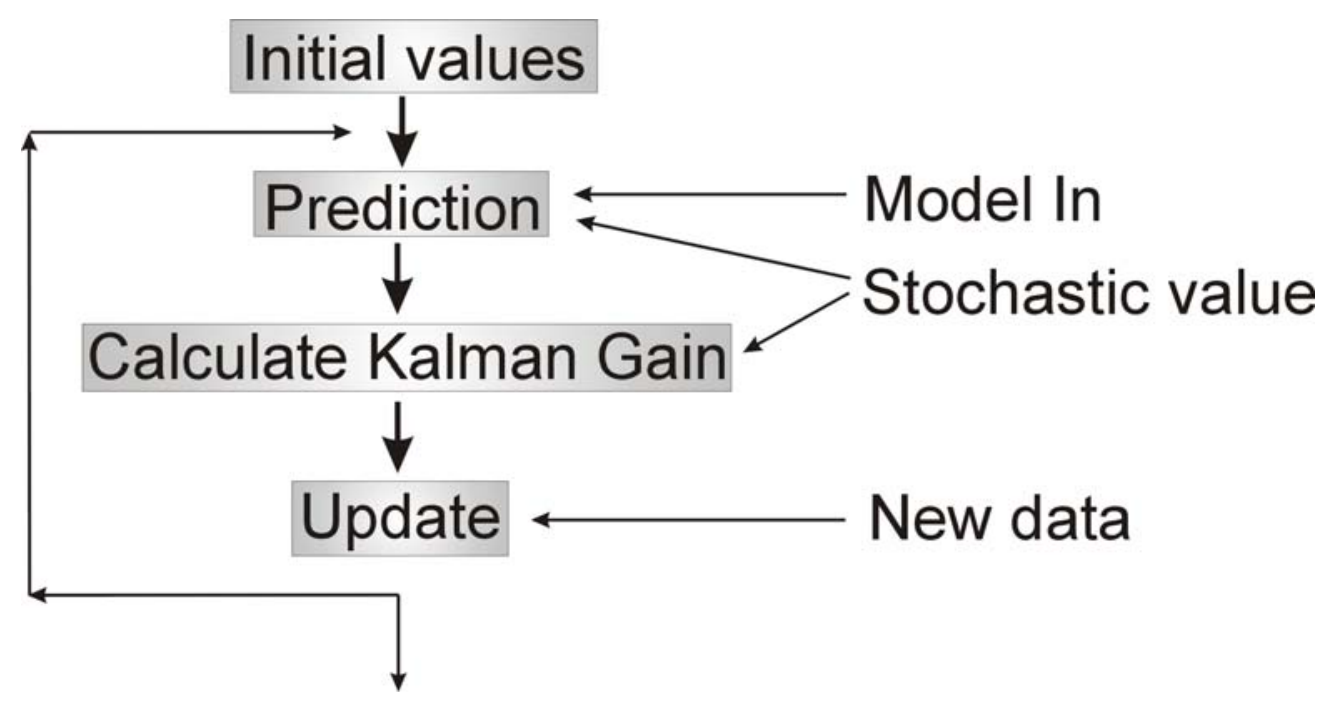

Fig. 9. Diagram of the Kalman Filter Processing

Using this method needs to correct modeling not only measurements but also process. Authors assumed that every brand of GNSS receiver can be use. TRACK software works with universal GNSS date format: RINEX 2.1 and 3.0 so above assumption is execute.

Same method was exposed in Military University of Technology. Laboratory trials with known parameters of extortion confirmed totally usefulness of this technique - method of measurements and calculating algorithms - for big construction monitoring like bridges, buildings or dams.

\section{CONCLUSIONS}

Results show that using this method authors are able to monitor construction behavior. GPS technology enable to:

- get information about dynamic behavior of construction caused by exterior loading caused by traffic, extreme weather conditions and other dangerous extortions like earth quake

- detect overload trucks inducing adverse micro-breaks in elements of a construction

- get real information about eccentric construction overload (what can be seen on Fig. 5) when one side of the road (construction) is load and the other is not.

- collected data from permanent, long-term observations can help to bridge servicing crew to rationalize outlay related with support good condition of the construction

- permanent GPS RTK (Network RTK) - ASG-EUPOS installation could be simple, reliable and fast source of information about normal and abnormal behavior of the construction in real time (Wawrzyn, Antosiewicz, 2003) 


\section{REFERENCES}

1. Beser J., Parkinson B.W., (1982). The application of NAVSTAR differential GPS in the civilian community. Navigation, 29(2), 107-136

2. Chmielewski T., Zębaty Z., (1998) Podstawy dynamiki budowli - ARKADY, Warszawa

3. Cosser E. (2004), Bridge deflection monitoring and frequency identification with single frequency GPS receiver, Institute of Engineering Surveying and Space Geodesy, University of Nottingham, UK

4. Czudek H., Wysocki A. (2005), Trwałość mostów drogowych; WKŁ Warszawa

5. Figurski M., Chmielewski M., Kroszczyński K., Kamiński P., Gałuszkiewicz M., Wrona M., (2007) System autorski WAT, „GEODETA” nr. 12 (151)

6. King, R.W. \& Bock, Y. (2006). Documentation of the GAMIT GPS analysis software v.10.21. in GAMIT, Massachusetts Institute of Technology and Scripps Institution of Oceanography

7. Lamparski J. (2001), Navstar GPS od teorii do praktyki, Wydawnictwo Uniwersytetu Warmińsko-Mazurskiego.

8. Przywara J. (2007), GPS na moście, „GEODETA” nr. 10(149)

9. Roberts G.W., Meng X., Meo M., Dodson A., Cosser E., Iuliano E., Morris A. (2003); A remote bridge health monitoring system using computational simulation and GPS sensor data -Institute of Engineering Surveying and Space Geodesy, University of Nottingham, UK; Collage of Aeronautics, Cranfield University, UK

10. Roberts G.W., Cosser E., Meng X., Dodson A. (2004) Highfrequency deflection monitoring of bridges by GPS; Institute of Engineering Surveying and Space Geodesy, University of Nottingham, UK

11. Szpecht C. (2007), System GPS, Pelplin.

12. Wawrzyn J. Antosiewicz M. (2003), Aktywna Sieć Geodezyjna ASG-PL. Podstawowe cele, struktura, zastosowanie, kierunki rozwoju. Seminarium "Otwarcie Centrum Zarządzania Aktywną Siecią Geodezyjną ASG-PL" Katowice, 25 luty.

Received: 2008- 04-21,

Reviewed: 2008-05-11,

Accepted: 2008-07-07. 